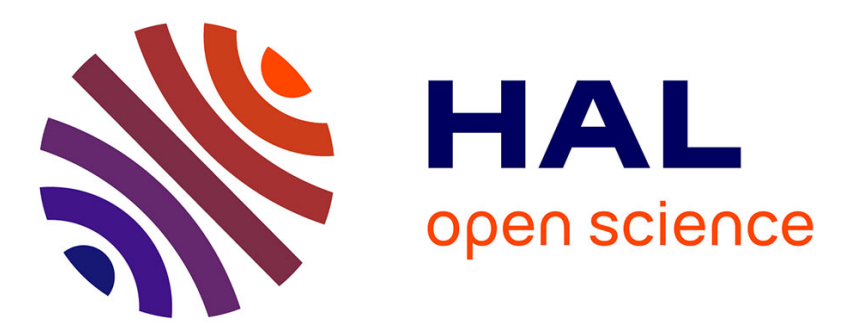

\title{
Alternative splicing determines the interaction of SMRT isoforms with nuclear receptor-DNA complexes
}

\author{
Flavie Faist, Stephen Short, Gg Kneale, Colin R Sharpe
}

\section{To cite this version:}

Flavie Faist, Stephen Short, Gg Kneale, Colin R Sharpe. Alternative splicing determines the interaction of SMRT isoforms with nuclear receptor-DNA complexes. Bioscience Reports, 2009, 29 (3), pp.143-149. 10.1042/BSR20080093 . hal-00479306

\section{HAL Id: hal-00479306 https://hal.science/hal-00479306}

Submitted on 30 Apr 2010

HAL is a multi-disciplinary open access archive for the deposit and dissemination of scientific research documents, whether they are published or not. The documents may come from teaching and research institutions in France or abroad, or from public or private research centers.
L'archive ouverte pluridisciplinaire HAL, est destinée au dépôt et à la diffusion de documents scientifiques de niveau recherche, publiés ou non, émanant des établissements d'enseignement et de recherche français ou étrangers, des laboratoires publics ou privés. 
SMRT-NR interactions

\section{ALTERNATIVE SPLICING DETERMINES THE INTERACTION OF SMRT ISOFORMS WITH NUCLEAR RECEPTOR-DNA COMPLEXES}

Short title: SMRT nuclear receptor interactions

\section{Flavie Faist ${ }^{1}$, Stephen Short $^{2}$, G. Geoff Kneale and Colin R. Sharpe}

Institute of Biomedical and Biomolecular Science, School Of Biological Science University of Portsmouth, Portsmouth, PO1 2DY, UK

${ }^{1}$ Current address: INSERM 673, Hopital Saint Antoine, Batiment Kourilsky, 184 rue de faubourg St Antoine, 75571 Paris Cedex 12, France.

${ }^{2}$ Current address: Marine Biology Research Division, Scripps Institution of Oceanography, La Jolla, CA 92093-0202 USA

Key words: corepressor; CoRNR box; EMSA; retinoic acid; thyroid hormone receptor;

Address correspondence to Colin R. Sharpe, School of Biological Science, King Henry Building, King Henry $1^{\text {st }}$ St, Portsmouth PO1 2DY, UK.

Tel +442392 842022

Fax +442392842053

E-mail: colin.sharpe@port.ac.uk 


\section{Synopsis}

Signalling by small molecules such as retinoic acid is mediated by heterodimers consisting of a class II nuclear receptor and an RXR subunit. The receptors bind to DNA response elements and act as ligand-dependent transcription factors but, in the absence of signal, the receptors bind the corepressors SMRT and NCoR and repress gene expression. Alternative splicing of the SMRT transcript in mammals generates six isoforms containing 1, 2 or 3 CoRNR box motifs that are responsible for the interactions with nuclear receptors. We show that human cell lines express all six SMRT isoforms and then determine the binding affinity of mouse SMRT isoforms for RAR/RXR and three additional class II nuclear receptor-DNA complexes. This approach demonstrates the importance of the full complement of CoRNR boxes within each SMRT protein, rather than the identity of individual CoRNR boxes, in directing the interaction of SMRT with nuclear receptors. Each class of SMRT isoform displays a distinct feature as the 1-box isoform discriminates between DNA response elements, the 2-box isoforms promote high affinity binding to thyroid hormone receptor complexes and the 3-box isoforms show differential binding to nuclear receptors. Consequently, the differential deployment of SMRT isoforms seen in vivo could significantly expand the regulatory capacity of nuclear receptor signalling. 
SMRT-NR interactions

\section{Introduction}

The class II nuclear receptors (NRs) mediate signalling by small molecule ligands such as thyroid hormone and retinoic acid [1,2]. They act as heterodimers consisting of a class II receptor and an RXR subunit. The heterodimer binds a DNA element, adjacent to responsive genes, that consists of a six base pair direct repeat (DR) separated by a variable number of nucleotides. Retinoic acid receptor response elements, for example, can be DR-5, in which the direct repeats are separated by five base pairs, DR-2 or DR-1, whereas thyroid hormone response elements are usually organised as a DR-4 [3, 4]. Binding of the small molecule ligand to its receptor promotes association with coactivators but, in the absence of ligand, the coactivator dissociates to be replaced by a corepressor [5, 6]. The corepressor paralogues SMRT and NCoR [7-9] can each assemble a multicomponent repressor complex that includes histone deacetylases $[10,11]$ converting chromatin into a closed, inactive state [12]. The SMRT/NCoR N-terminal region assembles the repressor complex [7-9] whilst the C-terminal region encodes two domains that interact with nuclear receptors. The interaction domains include three motifs, or CoRNR boxes, with the consensus sequence I/L.X.x.I/H.I.x.X.x.I [13-15]. SMRT and NCoR interact with a wide range of class II NRs, an unusual feat that is even more remarkable given that the NRs bind direct repeat DNA response elements varying in the separation from 1 to 5 base pairs that will alter the arrangement of the NRs around the DNA helix.

In previous studies, short peptides corresponding to individual CoRNR boxes have been used to demonstrate and quantify the different affinities of the CoRNR boxes for specific nuclear receptors [15-17]. However, an additional complexity is provided by alternative splicing of the primary transcript which generates multiple corepressor isoforms [9, 18-22]. For NCoR, one outcome is the generation of RIP13 $\Delta 1$, an isoform lacking part of the C-terminal interaction region [23], whereas the alternative splicing of SMRT generates sixteen C-terminal isoforms in Xenopus and six in humans and mice [21]. The exclusion of exon $45 \mathrm{~b}$ varies the peptide sequence adjacent to the most $\mathrm{C}$-terminal CoRNR box whereas the complete exclusion of exon 45 removes the entire C-terminal CoRNR box. The alternative splicing of exon $38 \mathrm{~b}$ regulates the inclusion of another CoRNR box and consequently, mouse and human cells contain three classes of SMRT isoform that contain 3,2 or just 1 CoRNR box [21].

To determine whether the diversity of SMRT isoforms contributes to its function as a corepressor, it will be necessary to resolve a number of questions. The first is whether SMRT isoform expression is regulated. We have previously shown that this is the case, as the alternative splicing of SMRT in Xenopus generates isoforms expressed in developmental and tissue specific combinations [21]. The second question is whether the isoforms can perform specific roles in vivo. This has been addressed using an antisense oligonucleotide to eliminate the inclusion of exon 38b and therefore restrict the range of available SMRT isoforms in Xenopus. The resulting embryos have head and neuronal defects accompanied by changes in the expression levels of thyroid hormone responsive genes [24]. A remaining question is whether the isoforms differ in their affinity for nuclear receptors and in this report we analyse, in vitro, the interactions of mouse SMRT isoforms with a range of DNA-bound class II NRs. The results suggest that the complement of CoRNR box motifs within the $\mathrm{C}$-terminal interaction domains plays a significant role in the selectivity of SMRT-NR interactions. These findings are likely to impact on the regulatory capacity of nuclear receptor signalling

\section{Materials and Methods}

Generation of SMRT ID region isoform clones

cDNA derived from mouse brain was amplified with primers to exons 38 and 46, corresponding to amino acid residues 2023 to 2426 of mouse SMRT (NM_011424), to generate six bands. These 
were cloned into TA vectors (Invitrogen) and the inserts transferred to pGEX-4T-2 (GE Healthcare) to produce N-terminal GST fusion proteins (Fig. 1A, 1B).

Expression and purification of SMRT and NR proteins

Protein expression was induced by $1 \mathrm{mM}$ IPTG and cell pellets lysed by sonication in $10 \mathrm{mM}$ $\mathrm{NaCl}, 1 \mathrm{mM}$ EDTA, $10 \mathrm{mM}$ Tris-HCl (pH 8.2) (2-box and 3-box SMRT isoforms) or $10 \mathrm{mM}$ sodium phosphate buffer $\mathrm{pH} 7.4,140 \mathrm{mM} \mathrm{NaCl}, 2.7 \mathrm{mM} \mathrm{KCl}$ (1-box SMRT isoform). Proteins were purified from the supernatant on AKTA systems (GE Healthcare) by a HiTrap heparin HP column followed by SP sepharose HP ion exchange chromatography. The concentration of each protein was determined by UV spectroscopy using an extinction coefficient derived from each prptein sequence using the application ProtParam on the ExPasy web site and purity analysed by SDS polyacryalmide gel.

The coding region of clones for mouse TR $\alpha$, RXR $\beta$, VDR and PPAR $\gamma$ (from Prof. Evans, Salk Institute, San Diego, USA) and RAR $\alpha$ (Prof. Chambon, Institut de Génétique et de Biologie Moléculaire et Cellulaire, Illkirch, Strasbourg, France) were transferred to pET-21b (Novagen) and the proteins purified by His-trap chromatography.

\section{Generation of response element probes}

Equimolar amounts of complementary oligonucleotides were annealed by heating to $90^{\circ} \mathrm{C}$ for 15 minutes in $10 \mathrm{mM}$ Tris- $\mathrm{HCl}$ ( $\mathrm{pH} 8.2), 150 \mathrm{mM} \mathrm{NaCl}, 10 \mathrm{mM} \mathrm{MgCl}_{2}$, cooled to room temperature and then stored overnight at $4^{\circ} \mathrm{C}$. The short DNA duplexes were isolated through a Superdex 75 10/30 column to generate probes containing DR-5, -4, -3, -2 and -1 response elements corresponding to the elements found in characterised genes:

DR-5 5'GGGTAGGGTTCACCGAAAGTTCACTCGCCATGAA3' DR-4 5'GATCCTACTTATAGGTCACATGAGGTCAAGTTAC3' DR-3 5'GGGTAGAGGTCAGGAAGGTCACTCGCCATG3' DR-2 5'AGCTTGGGGGTCAGCAGGTCAGCTTGCA3'

$\beta R A R[25]$ $\mathrm{CMHC} \alpha[26]$

Osteocalcin [27]

FGF8 [28]

DR-1 5'TTCCGTACAGGTCACAGGTCACTCGAGATAT3'

One oligonucleotide of each pair was supplied labelled with the fluorescent tag hexachlorofluorescein (Hex) (Eurogentec).

EMSA gels and analysis

Each class II NR was combined on ice with bacterially expressed RXR $\beta$ in $15 \mathrm{mM}$ Tris- $\mathrm{HCl} \mathrm{pH}$ 7.6, $200 \mathrm{mM} \mathrm{KCl}, 2 \mathrm{mM}$ DTT, $1 \mathrm{mM}$ EDTA, 4.5\% v/v glycerol before the addition of $1 \mathrm{ng}$ Hexlabelled DNA probe. The complex formed for 15 minutes at room temperature before the addition of SMRT isoforms for 15 minutes at $4^{0} \mathrm{C}$. The samples were resolved on a $7 \%$ polyacryamide gel in $0.5 \mathrm{xTBE}$ at $4^{0} \mathrm{C}, 100 \mathrm{~V}$ for 60 minutes and fluorescence quantified on a Fujifilm FLA5000 phosphorimager using ImageGuage software.

Each experiment was performed in triplicate and the 'fraction bound' values plotted using GraphPad Prism (v4.0) software (GraphPad Software, San Diego, California). For each assay the points fitted to a nonlinear regression curve describing the binding of a ligand to a receptor where $\mathrm{Y}=\mathrm{B}_{\max } \cdot \mathrm{X} /\left(\mathrm{K}_{\mathrm{d}}+\mathrm{X}\right)$, in which $\mathrm{Y}$ is the fraction of NR-DNA complex bound, $\mathrm{X}$ is the molar concentration of the SMRT isoform and $\mathrm{B}_{\max }$, the maximal binding is fixed at 1.0. Equal weighting was given to each point. The apparent $\mathrm{K}_{\mathrm{d}}$ was taken to be the concentration of SMRT required for half-maximal binding and the apparent $\mathrm{K}_{\mathrm{a}}$ is the inverse of $\mathrm{K}_{\mathrm{d}}$. Statistically significant differences in $\mathrm{K}_{\mathrm{a}}$ were calculated using a pairwise Students t-test. This approach is likely to provide a simplified version of the actual binding model, but provides a means of comparing the interactions between SMRT isoforms and NR heterodimers. 
SMRT-NR interactions

Note on the nomenclature of SMRT isoforms

Both human and mouse SMRT consist of a core of 47 coding exons. The isoforms are named systematically after the missing exons. This annotation of the SMRT gene results in a one exon shift in numbering, exons 37 and 44 in Malartre et al., [24] are now exons 38 and 45. The isoform in which all exons are retained is termed SMRTct.

\section{Results}

Human cell lines exhibit different SMRT isoform profiles

RT-PCR using primers specific to the 3' coding region of the SMRT transcript detect six isoforms in mouse brain (Fig. 1A) corresponding to the alternative splicing of exons 38b, $45 \mathrm{~b}$ and 45 [19, 21, 22] (Fig. 1B). Equivalent primers used on cDNA from four human tumour cell lines show quantitative differences in SMRT isoform expression (Fig. 1A). The six mouse SMRT isoforms, consisting of a single 1-box isoform, three 2-box isoforms and two 3-box isoforms, were cloned and the bacterially expressed and purified proteins (Fig. 1C) used for subsequent analyses.

SMRT isoforms show differential binding to RAR/RXR complexes on $D R-5, D R-2$ and $D R-1$ response elements.

Nuclear receptors bind to direct repeats of the consensus A/GGGTCA. In these experiments, we used probes derived from the characterised response elements of identified responsive genes (see Materials and Methods). On both DR-5 and DR-2 the RXR component binds to the upstream, and RAR to the downstream half of the bipartite response element, but on a DR-1 response element the order is reversed [30]. To analyse the contribution of response element spacing and NR orientation to binding, the affinity of each of the six SMRT isoforms for RAR/RXR on DR-5, DR-2 and DR-1 response elements was assessed by EMSA (Fig 2A).

The 1-box SMRT isoform $(\Delta 38 \mathrm{~b} / 45)$ binds the RAR $\alpha / \mathrm{RXR} \beta$ DR-5 complex with a $\mathrm{K}_{\mathrm{a}}$ of 3.9 $\mu \mathrm{M}^{-1}$ (Fig. 2B). This is comparable to 2 -box SMRT $\Delta 38 \mathrm{~b}$, which describes a standard binding curve with a $\mathrm{K}_{\mathrm{a}}$ of $5.8 \mu \mathrm{M}^{-1}$ (Fig. $2 \mathrm{~B}$ ). In contrast, the 2-box SMRT isoforms $\Delta 38 \mathrm{~b} / 45 \mathrm{~b}$ and $\Delta 45$ show sigmoidal binding that may indicate co-operative binding to the RAR $\alpha / R X R \beta$ DR-5 complex (Fig. 2B). Compared to both 1-box and 2-box SMRT isoforms, the affinity of 3-box isoforms for the complex is decreased by an order of magnitude $\left(\mathrm{K}_{\mathrm{a}}=0.1 \mu \mathrm{M}^{-1}\right.$ and $\left.0.4 \mu \mathrm{M}^{-1}\right)$ (Fig. 2B).

On DR-2 and DR-1 response elements the 2-box isoforms show the greatest affinity for RAR $\alpha / \operatorname{RXR} \beta$ complexes (Fig. 3) whilst 3-box isoforms bind only weakly. The major difference is for 1-box SMRT ( $\triangle 38 \mathrm{~b} / 45)$, which binds the RAR $\alpha / \operatorname{RXR} \beta$ DR-5 response element complex around five times better than it binds the RAR $\alpha / \operatorname{RXR} \beta$ DR-2 or DR-1 complexes (Fig 3). As RAR $\alpha$ occupies the downstream half-site on a DR-2 but the upstream half-site on a DR-1 sequence, it suggests that it is the spacing of the response element, rather than NR order, that determines interaction with the 1-box SMRT isoform.

The binding of SMRT isoforms to a range of class II nuclear receptor DNA complexes

Although the general structure of the SMRT binding site is conserved across the nuclear receptor family [31], the nuclear receptors clearly differ in their ability to interact with individual CoRNR box peptides [19]. However, the affinities of the complete interaction domains of the six SMRT isoforms for a range of NRs have yet to be compared systematically. We therefore extended the EMSA analysis to three additional class II NRs, thyroid hormone receptor $\alpha$ (TR $\alpha$ ), vitamin D 
SMRT-NR interactions

receptor (VDR) and peroxisome proliferator activated receptor $\gamma(\operatorname{PPAR} \gamma)$, each combined with RXR $\beta$ and added to DR-4, DR-3 and DR-1 response elements respectively.

The 1-box SMRT isoform binds both the TR $\alpha / R X R \beta$ DR-4 and the VDR/RXR $\beta$ DR-3 complexes with an apparent $\mathrm{K}_{\mathrm{a}}$ greater than $3 \mu \mathrm{M}^{-1}$, an affinity comparable to that determined for the RAR $\alpha / \operatorname{RXR} \beta$ DR-5 complex (Fig. 4A). In contrast the affinity for the PPAR $\gamma / \operatorname{RXR} \beta$ DR-1 complex was less than $1 \mu \mathrm{M}^{-1}$ in agreement with the suggestion that spacing of the repeat element half sites is a major determinant of the 1-box SMRT interaction with NR-DNA complexes (Fig. 4A).

All 2-box SMRT isoforms bind most strongly to TR $\alpha / \mathrm{RXR} \beta$ heterodimers (Fig. 4B). In addition, the presence of exon $45 \mathrm{~b}$ in isoform $\Delta 38 \mathrm{~b}$ causes an almost three-fold increase in the affinity of SMRT for the TR $\alpha / R X R \beta$-DNA complex. A similar result has previously been seen for binding of 2-box SMRT isoforms to TR $\beta / R X R \alpha$ [19]. However, this sequence does not generally increase the affinity of 2-box SMRT for a NR-DNA complex since isoforms lacking exon $45 \mathrm{~b}(\Delta 38 \mathrm{~b} / 45 \mathrm{~b}$ and $\Delta 45)$ show equal or even higher affinity than SMRT $\Delta 38 \mathrm{~b}$ for the other NR combinations tested (Fig. 4B).

Compared to 2-box and 1-box SMRT isoforms, the 3-box isoforms bind NR-DNA complexes weakly, with two exceptions. In the first, the SMRTct isoform preferentially binds a TR $\alpha / R X R \beta$ complex and in the second, the $\Delta 45 \mathrm{~b}$ isoform preferentially binds a VDR/RXR $\beta$ complex (Fig. 4C). This demonstrates the differential activity of two splice isoforms that share identical CoRNR boxes. Together with the data from the 2-box SMRT isoforms suggests that the exon 45b encoded peptide includes sequences that specifically promote interaction with TR $\alpha$.

\section{Discussion}

Alternative splicing often generates multiple proteins from a single gene [32]. A current task is to understand the contribution that isoforms make to the efficient working of an organism. Ultimately this involves generating a catalogue of isoforms, detailing their biochemical properties and addressing their biological function. SMRT is a good candidate for this type of analysis as it is composed of discrete regions that can be analysed in isolation. We have characterised isoforms of the C-terminus, the region that interacts with NRs.

Individual CoRNR box peptides exhibit differential binding to NRs [13, 14, 16, 23, 33, 34]. Cohen et al. [16], showed that the centrally located SMRT CoRNR box 2, but not NCoR CoRNR box 2, preferentially binds RAR $\alpha$, suggesting that corepressor paralogues target different NR complexes. In other studies on $\mathrm{NCoR}, \mathrm{Hu}$ and colleagues [33] found that CoRNR box 2 binds strongly to RAR and that CoRNR box 1 binds RXR and TR $\beta$. In contrast Webb et al. [34] demonstrated strong binding of NCoR CoRNR box 3 to TR $\beta$ and suggested that the presence of the third box determines the specificity of NCoR for TR $\beta$. The subsequent finding that SMRT also contains a third CoRNR box [20] argues against this conclusion. In has also been suggested that CoRNR box 1 interacts preferentially with RXR while CoRNR boxes 2 and 3 confer specificity for the class II NR in the heterodimer $[6,16,18]$ However, the 2-box SMRT isoform, $\Delta 45$, lacking CoRNR box 1 still binds $\mathrm{TR} \alpha / \operatorname{RXR} \beta$ heterodimers with high affinity indicating that CoRNR box 1 is not essential for the binding of SMRT to class II/RXR heterodimers. Whilst individual CoRNR boxes clearly show differential binding, less is known about how the complete SMRT ID region interacts with NRs.

A comparison of 1, 2 and 3-box SMRT isoforms shows that their binding characteristics are determined by different features of the NR-response element complex 
SMRT-NR interactions

The 1-box isoform binds to NR-complexes on DR-5, DR-4 and DR-3 response elements but shows reduced affinity when these are on DR-2 and DR-1 response elements. Although the repeats of the response element are nominally closer on a DR-1 than a DR-5, the helical twist of DNA places the midpoints of each repeat on the same side of the DNA helix in a DR-5 but on almost opposite sides in a DR-1 response element (Fig. 4B). Retinoid signalling is unusual in that it can activate gene expression through both DR-5 and DR-2 response elements. The selective repression of DR-5 promoters by the 1-box SMRT isoform may provide an additional means to distinguish between genes regulated by DR-5 and DR-2 response elements in tissues, such as muscle, in which the 1-box SMRT isoform is the predominant corepressor [21].

2-box SMRT isoforms bind most strongly to $\mathrm{TR} \alpha / \mathrm{RXR} \beta$ heterodimers and with lower affinity to the other tested NR-DNA complexes (Fig. 5). The depletion of 3-box SMRT isoforms in Xenopus embryos causes increased repression of thyroid hormone responsive genes [24] and this is consistent with the replacement of low affinity 3-box isoforms with 2-box SMRT corepressor isoforms that have high affinity for $\operatorname{TR} \alpha / \operatorname{RXR} \beta$.

The 3-box SMRT isoforms bind NR-DNA complexes with the least affinity. This is somewhat surprising as the addition of the third box reduces the affinity of the two box form suggesting that it either alters the conformation of SMRT or competition between boxes destabilises binding.

Having quantified differences in the binding of SMRT isoforms to NR-DNA complexes, this information will now provide a framework for further functional experiments to determine the relationship between binding affinity in vitro and corepressor activity in vivo.

In addition to class II NR heterodimers, SMRT also binds class I steroid hormone homodimers [35] and it will be interesting to compare the binding activity of SMRT isoforms in this context. This may have clinical significance given the association between SMRT expression and poor patient outcome in breast cancer [36]. SMRT binding is not limited to NRs and interaction sites for a number of other transcription factors including Oct-1 and NFkB also map to the C-terminal region [37]. Nuclear corepressor diversity, both through the expression of NCoR and SMRT and alternatively spliced SMRT isoforms, may significantly expand the capacity to regulate NR signalling.

\section{Acknowledgements}

We thank Prof. Ron Evans, Prof. Pierre Chambon and Prof Malcolm Maden for clones. We are grateful to Matt Guille, Marianne Malartre and Sarah Thresh for informative comments, and members of the Kneale and Sharpe labs for advice and assistance. FF was a University of Portsmouth, IBBS Bursary PhD student, SS was funded by a BBSRC studentship. 
SMRT-NR interactions

\section{References}

1 Mangelsdorf, D. J. and Evans, R. M. (1995) The RXR heterodimers and orphan receptors. Cell 83, 841-850

2 Evans, R. M. (1988) The steroid and thyroid hormone receptor superfamily. Science 240, 889-895

3 Umesono, K., Murakami, K. K., Thompson, C. C. and Evans, R. M. (1991) Direct repeats as selective response elements for the thyroid hormone, retinoic acid, and vitamin D3 receptors. Cell 65, 1255-1266

4 Khorasanizadeh, S. and Rastinejad, F. (2001) Nuclear-receptor interactions on DNA-response elements. Trends Biochem Sci 26, 384-390

5 Xu, L., Glass, C. K. and Rosenfeld, M. G. (1999) Coactivator and corepressor complexes in nuclear receptor function. Curr Opin Genet Dev 9, 140-147

6 Privalsky, M. L. (2004) The role of corepressors in transcriptional regulation by nuclear hormone receptors. Annu Rev Physiol 66, 315-360

7 Chen, J. D. and Evans, R. M. (1995) A transcriptional co-repressor that interacts with nuclear hormone receptors. Nature 377, 454-457

8 Horlein, A. J., Naar, A. M., Heinzel, T., Torchia, J., Gloss, B., Kurokawa, R., Ryan, A., Kamei, Y., Soderstrom, M., Glass, C. K. and et al. (1995) Ligandindependent repression by the thyroid hormone receptor mediated by a nuclear receptor co-repressor. Nature 377, 397-404

9 Ordentlich, P., Downes, M., Xie, W., Genin, A., Spinner, N. B. and Evans, R. M. (1999) Unique forms of human and mouse nuclear receptor corepressor SMRT. Proc Natl Acad Sci U S A 96, 2639-2644

10 Li, J., Wang, J., Wang, J., Nawaz, Z., Liu, J. M., Qin, J. and Wong, J. (2000) Both corepressor proteins SMRT and N-CoR exist in large protein complexes containing HDAC3. Embo J 19, 4342-4350

11 Heinzel, T., Lavinsky, R. M., Mullen, T. M., Soderstrom, M., Laherty, C. D., Torchia, J., Yang, W. M., Brard, G., Ngo, S. D., Davie, J. R., Seto, E., Eisenman, R. N., Rose, D. W., Glass, C. K. and Rosenfeld, M. G. (1997) A complex containing $\mathrm{N}-\mathrm{CoR}, \mathrm{mSin} 3$ and histone deacetylase mediates transcriptional repression. Nature $387,43-48$

12 Kraus, W. L. and Wong, J. (2002) Nuclear receptor-dependent transcription with chromatin. Is it all about enzymes? Eur J Biochem 269, 2275-2283

$13 \mathrm{Hu}$, X. and Lazar, M. A. (1999) The CoRNR motif controls the recruitment of corepressors by nuclear hormone receptors. Nature 402, 93-96

14 Perissi, V., Staszewski, L. M., McInerney, E. M., Kurokawa, R., Krones, A., Rose, D. W., Lambert, M. H., Milburn, M. V., Glass, C. K. and Rosenfeld, M. G. (1999) Molecular determinants of nuclear receptor-corepressor interaction. Genes Dev 13, 3198-3208

15 Nagy, L., Kao, H. Y., Love, J. D., Li, C., Banayo, E., Gooch, J. T., Krishna, V., Chatterjee, K., Evans, R. M. and Schwabe, J. W. (1999) Mechanism of corepressor binding and release from nuclear hormone receptors. Genes Dev 13, 3209-3216

16 Cohen, R. N., Brzostek, S., Kim, B., Chorev, M., Wondisford, F. E. and Hollenberg, A. N. (2001) The specificity of interactions between nuclear hormone 
receptors and corepressors is mediated by distinct amino acid sequences within the interacting domains. Mol Endocrinol 15, 1049-1061

17 Makowski, A., Brzostek, S., Cohen, R. N. and Hollenberg, A. N. (2003) Determination of nuclear receptor corepressor interactions with the thyroid hormone receptor. Mol Endocrinol 17, 273-286

18 Seol, W., Mahon, M. J., Lee, Y. K. and Moore, D. D. (1996) Two receptor interacting domains in the nuclear hormone receptor corepressor RIP13/N-CoR. Mol Endocrinol 10, 1646-1655

19 Goodson, M. L., Jonas, B. A. and Privalsky, M. L. (2005b) Alternative mRNA splicing of SMRT creates functional diversity by generating corepressor isoforms with different affinities for different nuclear receptors. J Biol Chem 280, 74937503

20 Malartre, M., Short, S. and Sharpe, C. (2004) Alternative splicing generates multiple SMRT transcripts encoding conserved repressor domains linked to variable transcription factor interaction domains. Nucleic Acids Res 32, 46764686

21 Short, S., Malartre, M. and Sharpe, C. (2005) SMRT has tissue-specific isoform profiles that include a form containing one CoRNR box. Biochem Biophys Res Commun 334, 845-852

22 Goodson, M., Jonas, B. A. and Privalsky, M. A. (2005a) Corepressors: custom tailoring and alterations while you wait. Nucl Recept Signal 3, e003

23 Downes, M., Burke, L. J., Bailey, P. J. and Muscat, G. E. (1996) Two receptor interaction domains in the corepressor, N-CoR/RIP13, are required for an efficient interaction with Rev-erbA alpha and RVR: physical association is dependent on the E region of the orphan receptors. Nucleic Acids Res 24, 4379-4386

24 Malartre, M., Short, S. and Sharpe, C. (2006) Xenopus embryos lacking specific isoforms of the corepressor SMRT develop abnormal heads. Dev Biol 292, 333343

25 Sucov, H. M., Murakami, K. K. and Evans, R. M. (1990) Characterization of an autoregulated response element in the mouse retinoic acid receptor type beta gene. Proc Natl Acad Sci U S A 87, 5392-5396

26 Ikeda, M., Wilcox, E. C. and Chin, W. W. (1996) Different DNA elements can modulate the conformation of thyroid hormone receptor heterodimer and its transcriptional activity. J Biol Chem 271, 23096-23104

27 Demay, M. B., Gerardi, J. M., DeLuca, H. F. and Kronenberg, H. M. (1990) DNA sequences in the rat osteocalcin gene that bind the 1,25-dihydroxyvitamin D3 receptor and confer responsiveness to 1,25-dihydroxyvitamin D3. Proc Natl Acad Sci U S A 87, 369-373

28 Brondani, V., Klimkait, T., Egly, J. M. and Hamy, F. (2002) Promoter of FGF8 reveals a unique regulation by unliganded RARalpha. J Mol Biol 319, 715-728

29 Tugwood, J. D., Issemann, I., Anderson, R. G., Bundell, K. R., McPheat, W. L. and Green, S. (1992) The mouse peroxisome proliferator activated receptor recognizes a response element in the 5' flanking sequence of the rat acyl CoA oxidase gene. Embo J 11, 433-439 
30 Kurokawa, R., DiRenzo, J., Boehm, M., Sugarman, J., Gloss, B., Rosenfeld, M. G., Heyman, R. A. and Glass, C. K. (1994) Regulation of retinoid signalling by receptor polarity and allosteric control of ligand binding. Nature 371, 528-531

31 Xu, H. E., Stanley, T. B., Montana, V. G., Lambert, M. H., Shearer, B. G., Cobb, J. E., McKee, D. D., Galardi, C. M., Plunket, K. D., Nolte, R. T., Parks, D. J., Moore, J. T., Kliewer, S. A., Willson, T. M. and Stimmel, J. B. (2002) Structural basis for antagonist-mediated recruitment of nuclear co-repressors by PPARalpha. Nature 415, 813-817

32 Blencowe, B. J. (2006) Alternative splicing: new insights from global analyses. Cell 126, 37-47

33 Hu, X., Li, Y. and Lazar, M. A. (2001) Determinants of CoRNR-dependent repression complex assembly on nuclear hormone receptors. Mol Cell Biol 21, 1747-1758

34 Webb, P., Anderson, C. M., Valentine, C., Nguyen, P., Marimuthu, A., West, B. L., Baxter, J. D. and Kushner, P. J. (2000) The nuclear receptor corepressor (NCoR) contains three isoleucine motifs (I/LXXII) that serve as receptor interaction domains (IDs). Mol Endocrinol 14, 1976-1985

35 Smith, C. L., Nawaz, Z. and O'Malley, B. W. (1997) Coactivator and corepressor regulation of the agonist/antagonist activity of the mixed antiestrogen, 4hydroxytamoxifen. Mol Endocrinol 11, 657-666

36 Green, A. R., Burney, C., Granger, C. J., Paish, E. C., El-Sheikh, S., Rakha, E. A., Powe, D. G., Macmillan, R. D., Ellis, I. O. and Stylianou, E. (2007) The prognostic significance of steroid receptor co-regulators in breast cancer: corepressor NCOR2/SMRT is an independent indicator of poor outcome. Breast Cancer Res Treat

37 Jepsen, K. and Rosenfeld, M. G. (2002) Biological roles and mechanistic actions of co-repressor complexes. J Cell Sci 115, 689-698 
SMRT-NR interactions

Figure legends

Figure 1 SMRT C-terminal isoform expression in vivo and in vitro

A. SMRT isoform profiles generated by RT-PCR using RNA from the breast cancer cell line MCF 7 (B), the ovarian tumour line JAMA (O), the oesophageal tumour line OE33 (E) and the colorectal cancer line LS174T (C) compared to the profile of isoforms seen in mouse brain (Mb). Although there are similarities, each cell line has a quantitatively different profile.

B. The region of the SMRT gene from exon 38 to 46 . The dark boxes indicate alternatively spliced exons $38 \mathrm{~b}$ and $45 \mathrm{~b}$, whilst the pale exon 45 along with exon $45 \mathrm{~b}$ is also alternatively spliced. The mid-tone boxes represent the 3 CoRNR boxes with CoRNR box- 2 split between exons 40 and 41.

C. SDS polyacrylamide gel of the six SMRT isoforms expressed and purified from bacteria.

Figure 2 The binding of SMRT isoforms with RAR $\alpha / R X R \beta$ heterodimers on a DR-5, response element

A. Representative examples of EMSA gels showing the supershift (arrowed SS) of the RAR $\alpha / R X R \beta$ complex (lane $C$ ) by the addition of increasing amounts of SMRT from 0.07 to 1.2 $\mu \mathrm{M}$. (Lane $\mathrm{P}$, free probe)

B. Binding curves for the SMRT isoforms. For 2-box isoforms $\Delta 38 \mathrm{~b} / 45 \mathrm{~b}$ and $\Delta 45$, the points deviate from the fitted curve and the calculated binding constants are consequently an approximation. The sigmoidal curve in these cases may indicate cooperative binding. 3-box SMRT $\Delta 45 \mathrm{~b}$ shows little or no binding to the RAR $\alpha / R X R \beta$ complex on a DR-5 response element.

Figure 3

A comparison of the binding constants for the SMRT isoforms on DR-5, DR-2 and DR-1 response elements

The $\mathrm{K}_{\mathrm{a}}$ for each SMRT isoform was calculated from EMSA gels for RAR $\alpha / \mathrm{RXR} \beta$ complexes on each response element. Error bars represent the standard deviation of the calculated binding constants. There is a decrease in the binding affinity of the 1-box isoform for DR-2 and DR-1 compared to a DR-5 response element.

Figure 4 A comparison of the binding of SMRT isoforms to type II nuclear receptors

A. Binding of the 1-box isoform. Results confirm the observation that the1-box isoform binds significantly better to DR -3 to 5 than to more closely spaced response elements $(* p<0.05)$. Response elements are shown on a linear representation of DNA and on a DNA helix. On the helix, the midpoints of the DR-5 repeat elements (bars) are in close proximity. For a DR-1 the midpoints are almost on opposite sides of the helix.

B. Binding of the 2-box isoforms. The 2-box isoforms show a clear preference for the $\mathrm{TR} \alpha / \operatorname{RXR} \beta$ complex. The exon $45 \mathrm{~b}+$ encoded peptide present in $\Delta 38 \mathrm{~b}$ significantly enhances the affinity of the SMRT for this complex compared to isoform $\Delta 38 \mathrm{~b} / 45 \mathrm{~b}\left({ }^{*} \mathrm{p}<0.05\right.$; error bars, SD). C. Binding of the 3-box isoforms. The binding of 3-box SMRT isoforms to NR-response element complexes is weak, with the exception of binding to TR and VDR complexes. In these cases, the presence of the exon $45 \mathrm{~b}$ encoded peptide promotes binding to $\mathrm{TR} \alpha / \mathrm{RXR} \beta$ whereas its absence promotes binding to VDR/RXR. $\left({ }^{*} \mathrm{p}<0.05\right)$ 
SMRT-NR interactions

\section{Faist Figure 1}

A

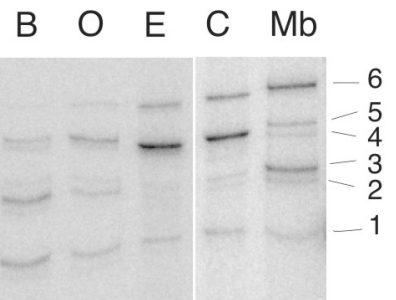

B

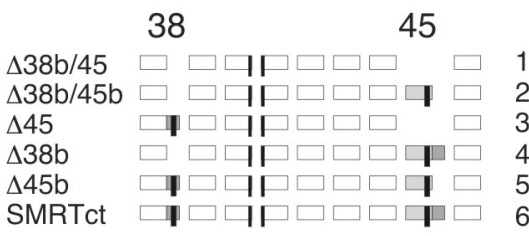

C

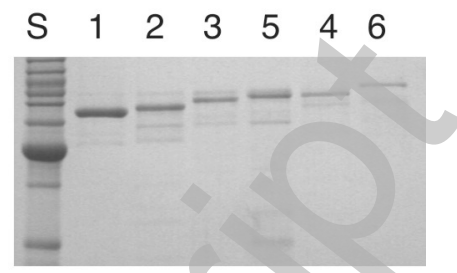

\section{Faist Figure 2}
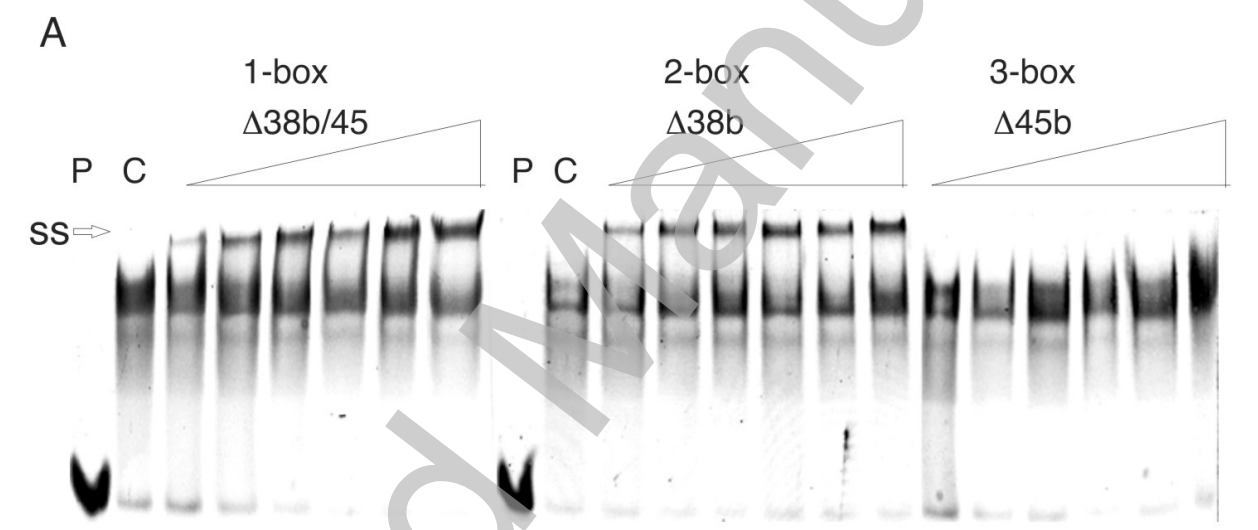

B

$\Delta 38 \mathrm{~b} / 45(1)$

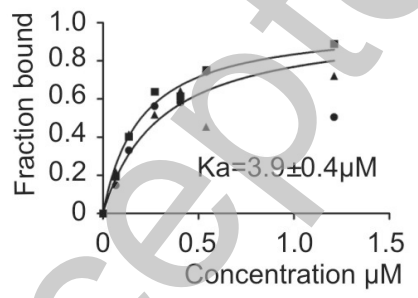

$\Delta 38$ b (2)

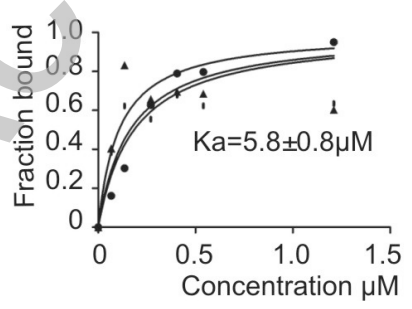

$\Delta 38 b / 45 b(2)$

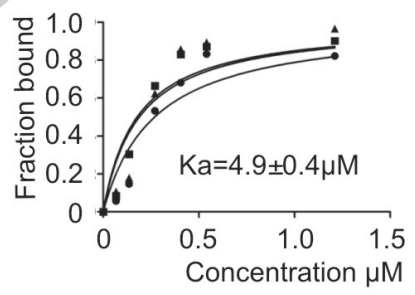

$\Delta 45$ b (3)

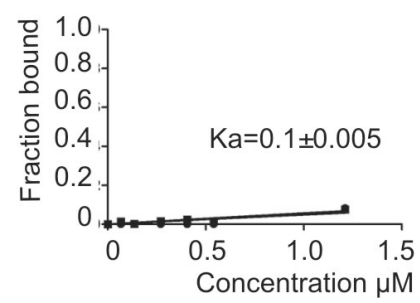

$\Delta 45(2)$

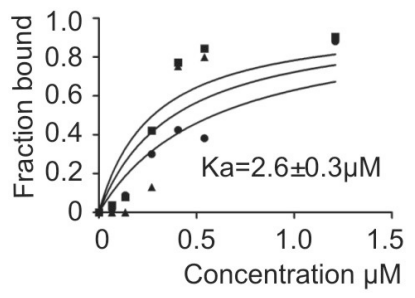

SMRTct (3)

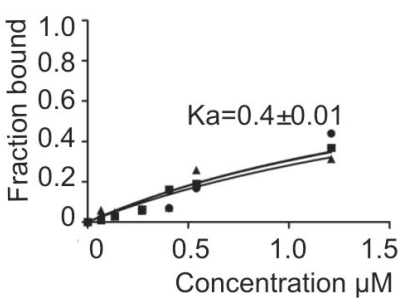


SMRT-NR interactions

\section{Faist Figure 3}

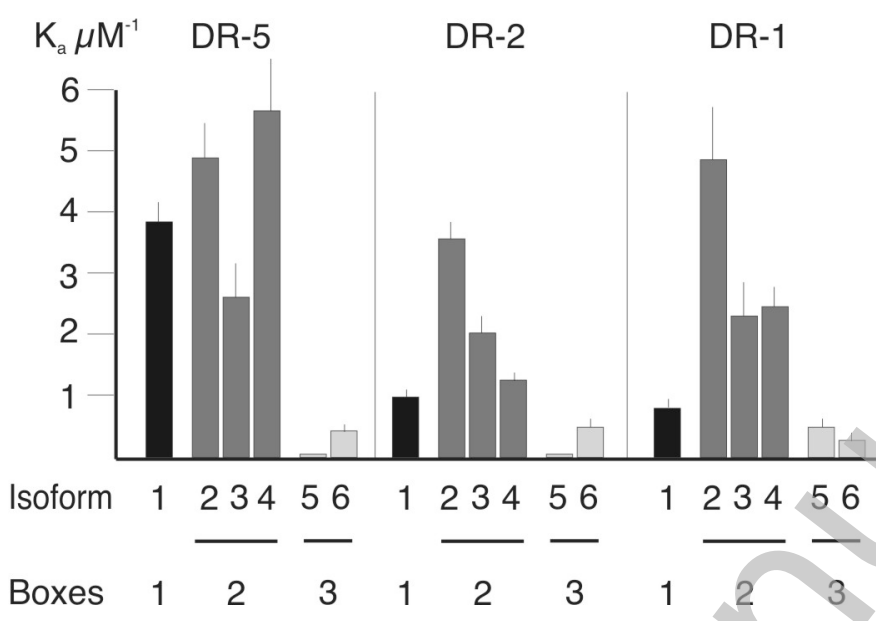

Faist Figure 4

A

$$
\begin{aligned}
& \text { 1-box } \\
& \square \square \square \square \square \square \square \square \square
\end{aligned}
$$

$\mathrm{K}_{\mathrm{a}}$<smiles>[M]1CCCCC1</smiles>

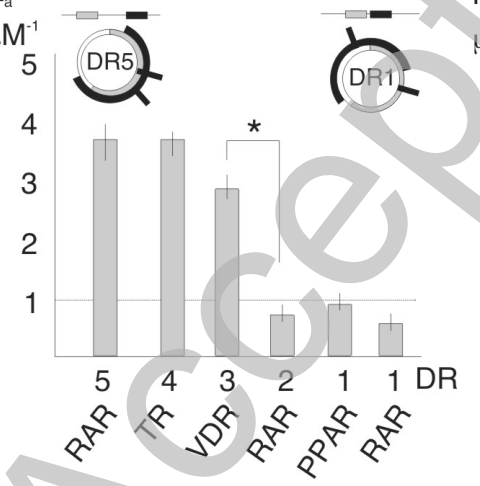

$\mathrm{B}$
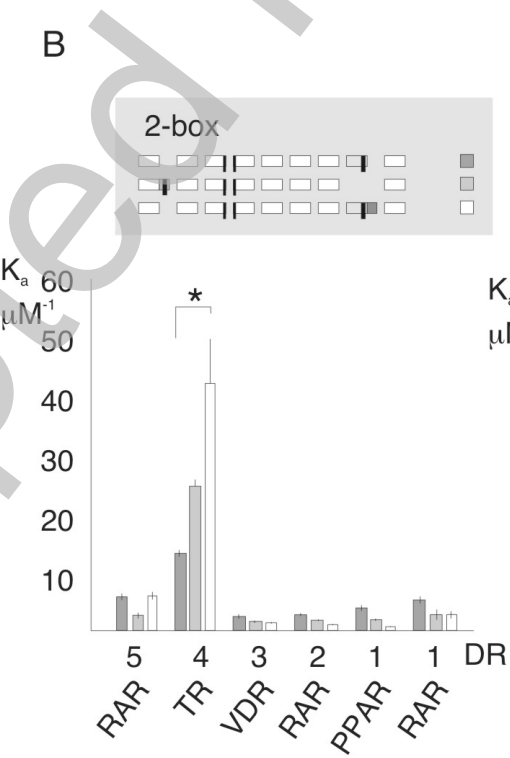

C

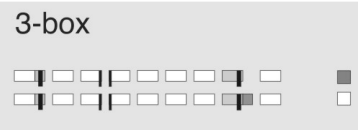

$\mathrm{K}_{\mathrm{a}}$ $\mu \mathrm{M}^{-15}$

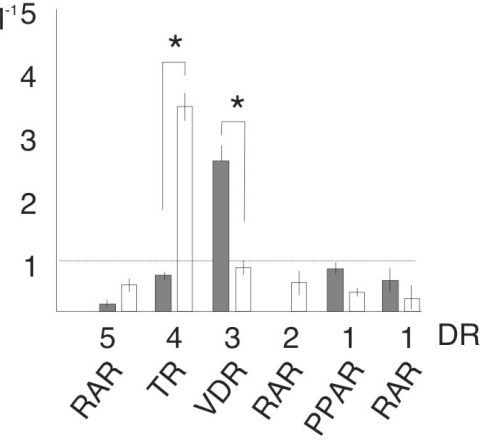

